\title{
Study of the Relationship of Workplace Person- environment Fit, Country Identification and Affective Commitment -Evidence of Chinese Immigrant Wives in
} Taiwan

\author{
By Philip Cheng-Fei Tsai* \\ Yu-Fang Yen ${ }^{\dagger}$
}

Because of rapid global development, firms generally use a multiple-faceted strategy in the application of human resources. Immigrant wives have been a source of complementary manpower. Compared with the common problems of culture and life, adjustment to these jobs may be more difficult for them. Most immigrant wives in Taiwan are originally from China and experience the additional challenge of national identification. All of these difficulties in workplace decrease their commitment to firms, affect their job performance, reduce their willingness to contribute their capabilities, and eventually increase social costs. To manage the critical HRM issue, this study initially explored $P-E$ fit and affective commitment by conducting empirical research on 300 Chinese immigrant wives in Taiwan. The findings reveal that their $P$ E-Fit positively affects their affective commitment to firms; similarly, their national identification to Taiwan strengthens the stated results. However, the different dimensions of P-E fit had different influence effects. The implications of this study will benefit future research on immigrant employees and HRM practices.

Keywords: affective commitment, workplace, immigrant wives, person-environment fit, country identification

\section{Introduction}

The application of multi-cultural HR has become one of the crucial managerial strategies for firms to upgrade their global competitiveness (Sing and Point, 2004). Using multi-cultural HR helps to stimulate creativeness, solve problems, and eliminate managerial bottlenecks (Cox and Blake, 1991; Jackson, 1992; Weigand, 2007). Taiwanese firms also recruit employees with hetero-cultural backgrounds to increase their competitiveness (Lee, 2006).

In the late $20^{\text {th }}$ century, the mobility of the population was frequent. The main factor influencing Taiwanese social structure is the introduction of foreign labor and the popularity of cross-national marriages (Chu, 2005). According to the statistics of the Ministry of Internal Affairs, 452,717 immigrant wives resided in Taiwan. Among them, 279,377 were Chinese immigrant wives, accounting for $62 \%$ of the total. They have become a crucial source of labor for Taiwanese firms.

\footnotetext{
${ }^{*}$ Full Professor, Wenzao Ursuline University of Languages, Taiwan.

${ }^{\dagger}$ Associate Professor, National Quemoy University, Taiwan.
} 
However, immigrant wives have low employability because of inadequate adjustment to their workplaces. An investigation showed that $55.96 \%$ of immigrant wives participate in the job market (Ministry of Internal Affairs, 2008). Cheng (2010) indicated that immigrant wives experience considerable difficulties in their workplace, such as lack of sufficient job-related skills, various culture-adjustment problems, and social exclusion. Compared with immigrant wives of other nationalities, Chinese immigrant wives have fewer barriers in adjusting to local customs and languages; however, they encounter a problem of national identification because of conflicting political standpoints. Prior studies have indicated that national identification affects the psychology and behavior of people (Keillor and Hult, 1999; Chiang, 1998; Chu and Liu, 2005). This study proposes that the level of national identification moderates their fitness to jobs. Failure to adjust to the workplace causes businesses to lose a substantial number of diversified employees and leads to personal misfortune because of the inability of employees to provide for their respective families. However, most studies that have investigated this issue were based on the perspective of sociology instead of HRM. This study used the perspective of HRM, which can help firms to understand the psychological and behavioral characteristics of immigrant wives and become a valuable reference for future recruitment, training, and management.

According to related literature focusing on organizational behavior, person-environment fit (P-E Fit) explains the positive correlation results of job satisfaction, organizational commitment, and personal career achievement (Bretz and Judge, 1994). Namini, et al. (2010) also proposed that P-E Fit can effectively explain the behaviors of new members in a group. The subdimensions of P-E Fit include person-job fit, person-organization fit, personsupervisor fit, and person-group fit. Person-group fit has significant correlations with employee resignation intention, organizational commitment, organizational commitment, job satisfaction, employee performance, and career decisions (Caldwell and O'Reilly, 1990; Kristof-Brown, 1996; Saks and Ashforth, 1997; Cable and DeRue, 2002; Kristof-Brown, et al. 2005; Chuang and Lin, 2005; Young and Hurlic, 2007). Organizational commitment has a positive effect on employee work outcomes, such as increasing productivity, and job quality, strengthening employee loyalty, and decreasing employee turn-over rates. Among the three organizational commitments, Meyer, Allen, and Smith (1993) indicated that the bonding between employees and organizational affection increases in conjunction with the affective commitment of employees, which further supports and strengthens the existing value of the organization. Therefore, it is the strongest and most consistent predictor of organizationally desired outcomes, such as employee retention commitment (e.g. Herndon, et al. 2001; Mohamed, Taylor, and Hassan, 2006).

In summary, this argument may have a substantial explanatory and predictive ability when conducting studies on the fit of immigrant wives to the workplace. This study will contribute to firms in HRM practices (e.g., selection, training, evaluation, and rewarding of employees). To verify if the 
theory applies to examining the job fit issue of immigrant wives, the following research questions were formulated:

1. Will the P-E Fit of Chinese immigrant wives strengthen their affective commitment?

2. Will the P-E Fit and other sub-dimensions of Chinese immigrant wives respectively influence their affective commitment to firms?

3. Will the national identification of Chinese immigrant wives toward Taiwan influence P-E Fit and the affective commitment?

\section{Literature Review}

\section{Immigrant Wives' Difficulty in Job Place Fit}

According to a prior investigation (Ministry of Internal Affairs, 2011), 452,717 immigrant spouses reside in Taiwan; among them, 30,588 are male and 422,129 are female. Chinese immigrant wives account for $67 \%$ of all immigrant spouses (Chinese: 279,377; Vietnamese: 85,130; and Indonesian: 26,693).

Most immigrant wives are required to work to increase their family incomes. But the participation of immigrant wives in the job market is only $56.0 \%$ (Ministry of Internal Affairs, 2008). Among their career decisions, $35.3 \%$ of Chinese immigrant wives have chosen to work in the manufacturing industry and $21.5 \%$ chose to work in hotels and catering services. Their barriers in the workplace include internal and external factors. Internal factors include language barriers (verbal and written forms), cultural differences, low education levels, and lack of necessary knowledge at work. External factors include negative social cognition, gender/racial discrimination, lack of social resources, governmental restriction (employment rights, the acquirement of identification), and unrecognized educational levels. These difficulties have caused most of them to remain in lower positions and to accept lower salaries, thereby having equal (occasionally more) work and unfair pay (Wu, 2004; Chen, 2007). Cheng (2010) further indicated that, in addition to these obstacles, social exclusion is a crucial difficulty experienced by immigrant wives in their workplaces. Social exclusion refers to exclusion from the labor market, involvement, decisions, and interpersonal relations. These obstacles prevent them from fitting in at their workplaces and helping with the financial requirements of their families, which lead to social problems. In addition to these problems, the concern of national identification discourages Chinese immigrant wives from working away from their families. Most of them felt that they were treated as Chinese instead of Taiwanese, and the feeling of being treated unequally caused them to doubt whether they were Taiwanese or Chinese. Such psychological barriers increase the difficulty of fitting in at the workplace. Similarly, firms are reluctant to hire them, which cause firms to lose an employable workforce. 
The study determined the difficulties experienced by Chinese immigrant wives in fitting in at the workplace based on the theoretical perspectives of P-E Fit, affective commitment, and national identification.

\section{Person-Environment Fit (P-E Fit)}

P-E Fit is a common research theory when investigating the manner in which people fit their environments. Previous research indicated that P-E Fit had positive correlations with employee career achievements, personal dedication to career development, and organizational commitment (Hollenbeck, 1989; Chatman, 1991; Bretz and Judge, 1994; Harris and Mossholder, 1996; Kristof-Brown, 1996). The better the individual characteristics fit the environment, the more positive behaviors and beneficial attitudes they exhibit (Holland, 1985).

The theory of P-E Fit is consistent with psychological and behavioral studies on new employees (Namini et al., 2010). Moreover, scholars categorized P-E Fit in various manners; for example, Judge and Ferris (1992) and Kristof-Brown (1996) proposed P-O Fit, P-G Fit, P-V Fit, and P-J Fit. However, from the theory of person-in-situation, P-J Fit and P-O Fit may not be sufficient to fully explain the behaviors of employees. Subordinatesupervisor fit is another crucial factor that can add to the construct of P-E Fit (Chuang and Lin, 2005). This study suggests that P-E Fit can be used to explain and predict the manner in which Chinese immigrant wives fit in at their workplaces.

\section{$\underline{\text { P-J Fit }}$}

P-J Fit describes the manner in which individual characteristics match the job (Edwards, 1991). Specifically, P-J Fit demonstrates the efficiency with which the job (the characteristics) satisfies the requirements of employees (goals, values, interests, and references), or the efficiency with which the capabilities of employees (e.g., personality, work experiences, and educational level) met the job requirements (such as standards set for achieving performance goals) (Chuang and Lin, 2005). Tinsley (2000) proposed that an excellent P-J Fit benefits people by (1) reducing stress, intention to change jobs, anxiety, absenteeism; (2) stabilizing emotions, improving psychological/ physical well-being, learning attitudes, alternatives on jobs; and (3) increasing organizational commitment, aggressiveness, job performance, creativity, career achievements, job satisfaction, and morale.

The ability to cope with the job was the main factor in P-E Fit; therefore, it can determine and predict if the qualifications and characteristics of Chinese immigrant wives enable them to cope with their jobs. 


\section{$\underline{\text { P-O Fit }}$}

P-O Fit indicates the level of fit between people and their organizational characteristics. Specifically, P-O Fit refers to the matching level between the personal characteristics, mentality, and attitudes of employees and organizational culture, strategic demands, norms, and values. Schneider (1987) proposed an ASA model (Attraction-Section-Attrition), which showed that people and organizations seek an acceptable balance point. Only those who remain at the firms are suitable employees. Kristof-Brown (1996) classified P$\mathrm{O}$ Fit into two dimensions: personal characteristic-organizational culture and climate fit, and personal supply-need-organizational supply need fit. The P-O Fit tends to be high when an organization satisfies personal needs and preferences, and personal capabilities fit organizational needs. Therefore, personal characteristics and organizations must work together to achieve optimal performance. When the P-O Fit is high, employees tend to exhibit superior performance and organizational commitment, and lower intention of leaving (Posner, Kouzes, and Schmidt, 1985; Cable and Judge, 1996; Chuang and Lin, 2005; Young and Hurlic, 2007).

The P-O Fit is crucial for Chinese immigrant wives because, when their personal characteristics and needs fit the organizational culture, they have superior job security. However, the P-O Fit involves organizational culture and the characteristics of pursuing efficiency, which is challenging for Chinese immigrant wives. Hence, this fit is a critical indicator to measure the efficiency with which Chinese immigrant wives match their workplaces.

\section{$\underline{\text { P-G Fit }}$}

P-G Fit refers to the efficiency with which people match their direct working groups (units). P-G Fit has a more significant correlation with organizational performance (Guzzo and Soerr, 1989), because the value-fit between people and their groups influence their interactions (Adkins, et al. 1996). Values represent the core beliefs about "what to do" and "what not to do." Values also interactively correlate with several specific beliefs, recognition, and attitudes (Ravlin and Meglino, 1987). A number of studies showed that the homogeneity of value (Haythorn, 1968; Klimoski and Jones, 1995), personality (Driskell, et al. 1987; Hackman and Morris, 1975), and goals (Shaw, 1981; Weldon and Weingart, 1993; Kristof-Brown and Stevens, 2001) influence groups and the behaviors and attitudes of members. The consistency of values has played a crucial role in interpersonal homogeneity. (Adkins et al., 1996) Meglino, Ravlin, and Adkins (1989), Chuang and Lin (2005), Young and Hurlic (2007) indicated that P-G Fit influences the job satisfaction, organizational commitment, and career plans of members.

$\mathrm{P}-\mathrm{G}$ Fit is also critical for Chinese immigrant wives, because they can obtain peer support in the workplace. Sufficient social support can help them to fit in at their workplaces; therefore, P-G Fit is a crucial indicator of the manner in which they fit. 


\section{$\underline{\text { P-S Fit }}$}

P-S Fit refers to the manner in which subordinates fit their supervisors (Lee, 2008). The elements in P-S Fit include leadership style, personal characteristics, values, and preferences. When the supervisors' preferences, personality traits, backgrounds (e.g., ages, educational levels, races, tenure), the manner in which they solve problems were similar to their subordinates, and they tended to attract one another, have more interactions, and have higher job satisfaction (Tsui and O'Reilly, 1989; Zenger and Lawrence, 1989). From the aspect of value fit, Meglino et al. (1989) indicated that, when the working vales, interests, and hobbies of supervisors were similar to those of their employees, the job satisfaction and organizational commitment of employees tended to be high, and supervisors had higher interpersonal trust and job trust in employees.

Weiss (1978) explored the effect of value fit between direct supervisors and subordinates and found that value fit had a positive correlation with the consideration of supervisors and the achievements and capabilities of employees. In summary, when the job value of employees fit that of their supervisors, the interaction and communication were positive.

The value fit is crucial and challenging for immigrant wives, because it requires more interpersonal interaction than P-J Fit, which has a more direct influence on their job performance than P-G Fit, and a stronger effect on the training, performance evaluation, and rewards of immigrant wives than $\mathrm{P}-\mathrm{O}$ Fit. Therefore, it is a crucial indicator to measure their workplace fit.

The higher the P-E Fit, the superior the work outcome (e.g., organizational commitment). Consequently, firms can reduce the managerial costs and improve performance when recruiting immigrant wives. P-E Fit can explain and predict the fitting problems of Chinese immigrant wives in their workplaces. The dimensions of P-E Fit have various effects on specific performance (Chuang and Lin, 2005). Therefore, researchers must investigate the dimension with the optimal fit and the inferior fit. These findings can help to improve the inferior dimensions and enhance the superior dimensions, which may help to reduce difficulties in job place fit.

\section{Affective Commitment}

Organizational commitment is the overall attitude of employees (recognition and responses in the workplace) toward the organizations (Millward and Brewerton, 2002). Organizational commitment can show the employee levels of loyalty, recognition, and participation in organizational activities. Research also showed that high organizational commitment can increase productivity/job quality, and strengthen employees' commitment, decrease turnover rates, and accelerate firm development (Allen and Meyer, 1991; Millward and Brewerton, 2002; Vandenberghe, et al. 2004; Carmeli, 2005; Mohamed et al., 2006). Hence, Organizational commitment is frequently used as an indicator of the work outcomes of employees. Meyer et al. (1993) 
divided Organizational commitment into three types, as follows: (1) affective commitment, (2) normative commitment, and (3) continuance commitment. Meyer and Allen (1990) found that affective commitment increased through the highly conformable feelings about their work experience and personal capabilities. Affective commitment increases when employees feel easy about their roles at work and are capable of managing their jobs. Mohamed et al., (2006) suggest that affective commitment is the strongest and most consistent predictor of organizationally desired outcomes. Chinese immigrant wives tend to focus on affective commitment, such as emotional attachment, identification, and involvement instead of normative commitment and continuance commitment. A crucial objective is the manner in which to make them a part of the society, because they leave their homeland to search for possible development in another country. When Chinese immigrant wives have an excellent fit with work, organizations, groups, and supervisors, it affects their affective commitment. Therefore, we propose the following hypotheses and sub-hypotheses.

H1: The P-E Fit of Chinese immigrant wives has a considerable influence on affective commitment.

Based on 4 sub-dimensions of P-E Fit, this study proposes the following 4 sub-hypotheses.

H1-1: Chinese immigrant wives' P-J Fit positively influences affective commitment.

H1-2: Chinese immigrant wives' P-O Fit positively influences affective commitment.

H1-3: Chinese immigrant wives' P-G Fit positively influences affective commitment.

H1-4: Chinese immigrant wives' P-S Fit positively influences affective commitment.

\section{National Identification}

National identification comprises two main components: the first component is a nation, which involves a number of concepts about one political community. Nation indicates that the community has a definite territory of land, common systems, and legislations that allows its members to clearly identify their belongingness (Smith, 1991). Another component is identification, which refers to the origin of family clans, belongingness, and approval. Overall, national identification means that a person recognizes the country to which he/she belongs and the type of country (Chiang, 1998). Among them, racial group identification, cultural identification (e.g., religion, history, and customs), and social political systems are frequently used to explore the relationship between society and its distinct characteristics. These 
distinct characteristics affect the behaviors of members (Huntington, 1993; Keillor, et al. 1996; Chiang, 1998; Keillor and Hult, 1999).

This study focused on Chinese immigrant wives. Comparatively, they had fewer barriers in local customs and languages; however, the confusion of national identification occurred. The confrontation between Taiwan and China has remained controversial and sensitive. The identification level of Chinese immigrant wives affects their daily life, interpersonal relationships, and workplace adjustment; for example, when they visit their families, their countrymen regard them as Taiwanese, even though they do not have Taiwanese identification. This perception has made them feel that they are no longer Chinese and further strengthens their belongingness and identification to Taiwan. However, they frequently feel that they are Chinese when living in Taiwan. They feel that they are content in Taiwan when interacting with original Taiwanese and being treated unfairly compared with Taiwanese people. Such contemplation and unfairness frequently made them anxious and disappointed (Chu and Liu, 2005). Additionally, Taiwan and China have various types of national identification (He and Guo, 2000). Taiwanese people propose that Taiwan is an independent country, and Chinese propose that Taiwan is an escaped province from China and the two straits will reunite. Decades of cross-strait confrontation has been listed by other countries as an area with a major conflict. Chinese immigrant wives who are raised and educated in China and move to Taiwan because of marriage generate the sensitive problem about their national identification. This psychological barrier increases difficulty in job place fit. Therefore, we propose the following hypothesis and sub-hypotheses.

Hypothesis 2: Chinese immigrant wives' national identification toward Taiwan will moderate the effect between P-G Fit and affective commitment.

Hypothesis 2-1: Chinese immigrant wives' national identification toward Taiwan will moderate the effect between P-J Fit and affective commitment.

Hypothesis 2-2: Chinese immigrant wives' national identification toward Taiwan will moderate the effect between P-O Fit and affective commitment.

Hypothesis 2-3: Chinese immigrant wives' national identification toward Taiwan will moderate the effect between P-G Fit and affective commitment.

Hypothesis 2-4: Chinese immigrant wives' national identification toward Taiwan will moderate the effect between P-S Fit and affective commitment.

The research construct is as figure 1, and target samples were selected from the two largest cities in Taiwan, Taipei and Kaohsiung for empirical examination. 
Figure1. The Research Framework

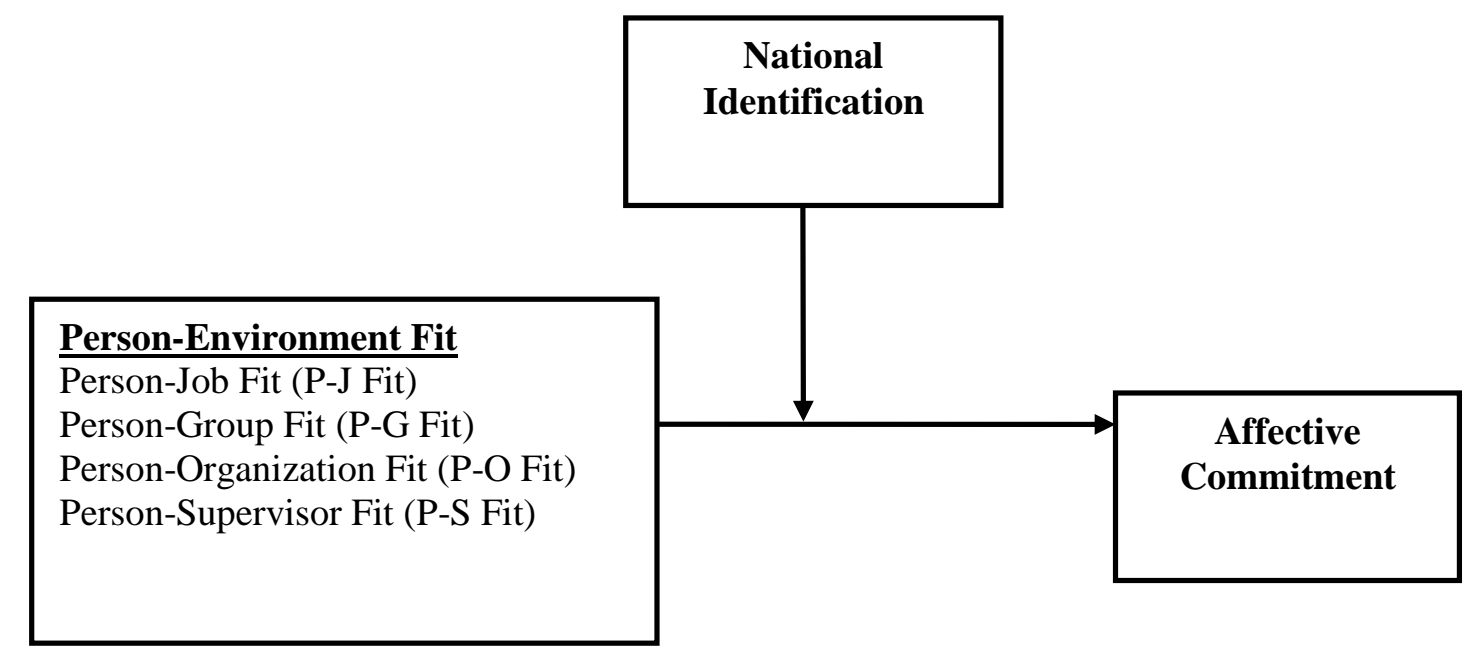

\section{Methodology}

Operational Definition and Questionnaire Design

All measures were developed based on previous literature and adapted modification to suit the specific context of Taiwanese society, and backtranslation was used to ensure consistency. The questionnaires used simplified characters, with which Chinese immigrant wives were familiar. P-E Fit means the fitting level between Chinese immigrant wives and their work environment, and comprises 4 dimensions.

\section{$\underline{\text { P-J Fit }}$}

P-J Fit indicates the manner in which the personal characteristics of Chinese immigrant wives fit the job. The 7 questions were modified from Cable and DeRue (2002), such as "Do my professional skills fit with my job content?" "Does the job meet my expectations?" and "Can I handle the job loading?"...etc.

\section{$\underline{\text { P-O Fit }}$}

P-O Fit indicates the manner in which Chinese immigrant wives fit the organizational culture and needs, including organizational culture, strategic needs, compliances, and values. A total of 5 questions were based on the studies by Autry and Dauhjerty (2003) and Cable and DeRue (2002); sample questions included "Are my values similar to firms," "Is the way I work acceptable for the firm?" and "Can I adjust to the firm?" ...etc. 


\section{$\underline{\text { P-G Fit }}$}

P-G Fit indicates the manner in which Chinese immigrant wives fit their direct working groups. The 7 questions were modified from the questionnaire of job value by $\mathrm{Wu}$, Lee, Liu, and Ou (1996). The sample questions were "Do I work closely with my colleagues?" "Do I communicate smoothly with colleagues?" and "Do I get along with my colleagues?" ...etc.

\section{$\underline{\text { P-S Fit }}$}

P-S Fit indicates the manner in which Chinese immigrant wives fit their supervisors. Seven questions on supervisors' leading styles, individual traits, values, and preferences were based on Personal and Organization Fit by Cable and DeRue (2002). The sample questions were "Do my supervisors communicate smoothly with me?" "Is the supervisor capable of managing risks?" and "Does the supervisor have decision power?" ...etc.

\section{$\underline{\text { Affective Commitment }}$}

This study used the affective commitment from the questionnaire of organizational commitment by Meyer et al. (1993). The affective commitment reflected how they felt regarding belonging to the organization, their emotional commitment to the organization, and the level to which they were involved with firm-related affairs. The sample questions were "Do I own the firm's problem?" "Do I have a strong belongingness to the firm?" and "Am I willing to serve this company?" ...etc.

\section{$\underline{\text { Country Identification }}$}

Country identification referred to the level of recognition of Chinese immigrant wives toward their Taiwanese identity. This study developed a measurement by modifying the concepts of NATID by Keiller et al. (1996) and Keillor and Hult (1999), cultural factors by Huntington (1993), and the overall coverage of national identification by Chiang (1998). The measurement in this research comprised 3 dimensions: racial group identification, culture identification, and socio-political system identification. The measurement comprises 8 questions, with sample questions such as "Do I agree with Taiwanese political systems?" "Am I proud of being a Taiwanese?" and "Do I agree with Taiwanese social customs?" ...etc.

\section{Control Variables}

The demographic factors (such as the staying duration in Taiwan, work experience, salaries, and the original country...etc.) created differentiation in P-E Fit, affective commitment, and national identification. Therefore, we treated them as control variables. 


\section{Sample and Data Collection}

We collected data from the following locations in 2011: Hsin-Yi District Bureau and Sung-Shan District Bureau in Taipei, Taipei Vocational Service Bureau, New Immigrant Association, Chinese Assistant and Help Association, Immigration Service Bureau (Kaohsiung Station) of Ministry of Internal Affairs, and Kaohsiung Immigrant Family Service Center. A total of 538 copies of questionnaires were dispatched after requesting the permission of Chinese immigrant wives. A total of 348 questionnaires were returned. After deducting 48 invalid questionnaires, the total number of effective questionnaires was 300. Most of the respondents were aged between 31 and 50 years old $(66.6 \%) ; 76.66 \%$ were high school and university graduates, 36\% lived in Taiwan between 4-6 years, 54\% had work experience in Taiwan between 1-5 years, 66\% had monthly income of approximately US\$600-\$ $1300,68 \%$ had full-time jobs, and $55 \%$ worked in the service industry.

\section{Findings/Results}

\section{Construct and Reliability Analysis}

This study conducted a factor analysis to gain the construct validity of the measurement tool. First, KMO and Barletts' Sphere test was conducted, followed by Principal Component Analysis, with an Eigen value greater than 1 . Factor loading was applied to delete questions. This study followed the principal of minimal requirement suggested by Hair, Anderson, Tatham, and Black (2010) to delete questions. The original questions on the dependent variable of P-E Fit included 26 items. Throughout the first factor analysis, no questions were deleted with a total explanatory variation of $76.677 \%$. After one factor analysis, no question items were deleted. The independent variable (the affective committed) had a total explanatory variation of $72.392 \%$. After the first factor analysis, no questions were deleted in the moderating variable (national identity), with a total explanatory variation of 55.265. The reliability analysis of each variable is shown in Table 1. The overall Cronbach's $\alpha$ was 0.7 .

Since this is a self-report questionnaire, we therefore adopt Harman's onefactor test to examine the common method variance problem (CMV) which was argued by Podsakoff, et al.(2003). The accumulated variance is $33.02 \%$ which reach to the acceptable level. 
Table1. Descriptive Statistic, Correlation Analysis, and Reliability

\begin{tabular}{|c|c|c|c|c|c|c|c|c|}
\hline & Mean & S.D & P-G Fit & P-S Fit & P-J Fit & P-O Fit & $\begin{array}{l}\text { National } \\
\text { ident. }\end{array}$ & $\begin{array}{l}\text { Affective } \\
\text { comm. }\end{array}$ \\
\hline P-G Fit & 3.382 & .821 & $(.952)$ & & & & & \\
\hline P-S Fit & 3.071 & .846 & $.334 * *$ & $(.921)$ & & & & \\
\hline P-J Fit & 3.298 & .834 & $.382 * *$ & $.209 * *$ & (.918) & & & \\
\hline P-O Fit & 3.299 & .765 & $.470 * *$ & $.316^{* *}$ & $.559 * *$ & $(.922)$ & & \\
\hline $\begin{array}{l}\text { National } \\
\text { identification }\end{array}$ & 3.323 & .554 & $.359 * *$ & $.340 * *$ & $.244 * *$ & $.316^{* *}$ & $(.879)$ & \\
\hline $\begin{array}{l}\text { Affective } \\
\text { commitment }\end{array}$ & 3.194 & .756 & $.482 * *$ & $.542 * *$ & $.380 * *$ & $.453 * *$ & $.449 * *$ & $(.923)$ \\
\hline
\end{tabular}

commitment

$* \mathrm{p}<.05 * * \mathrm{p}<.01 * * * \mathrm{p}<.001 \quad($ ): Cronbach's $\alpha$ 


\section{Descriptive and Correlation Analysis}

Table 1 shows the descriptive and correlation analysis of P-E Fit, affective commitment, and national identification. The descriptive analysis showed that the mean of P-G Fit reached the highest among all dimensions of P-E Fit; however, the standard deviation of P-S Fit reached the highest. We also conducted a Pearson Correlation to test the correlation levels among dependent variables, independent variables, and moderating variables. The results showed significant correlations among dependent, independent, and moderating variables. Table 1 shows the correlations.

\section{Variance Analysis}

The Variance analysis of demographic variables based on Chinese immigrant wives revealed that age has a significant Variance on national identification; the average monthly income has a significant Variance on P-O Fit, P-G Fit, P-D Fit, affective commitment, and national identification; job type has a significant Variance on P-G Fit. Consequently, the demographic variables with significant variations were treated as controlling variables.

\section{Regression Analysis and Hypotheses Testing}

After regression analysis, the influence of P-E Fit on affective commitment and the moderating effects on this relationship were determined, as shown in Table 2. Model 1 in Table 2 shows the influence of demographic variables (controlling variables) on affective commitment.

Model 2 in Table 2 shows that P-E Fit has a considerable influence on affective commitment. The analysis results $(\mathrm{P}$ value $<.01, \mathrm{~F}$ change $=43.793$, $\mathrm{R}^{2}=.470$ ) showed that the theory of P-E Fit can be applied to research on Chinese immigrant wives. The VIF (average of 1-10) revealed that the linear phenomena were in an acceptable range, which enabled us to treat them as individual and independent variables.

\section{Hypotheses 1: The Test on Principal Effects Commitment}

Model 2 in Table 2 shows that P-E Fit has a considerable influence on affective commitment. Hypotheses 1 was backed up by $\Delta \mathrm{R}^{2}=.47$ and a P-value smaller than .001 . The results from the 4 sub-dimensions were as follows: PValue of P-J Fit was smaller than .05 with $\beta$ value of .132 , which showed a significant influence; therefore, H1-1 was supported. P-Value of P-O Fit was greater than .05 with $\beta$ value of .84 , which showed no significant influence; therefore, H1-2 was not supported. P-Value of P-G Fit was smaller than 0.000 with $\beta$ value of .291 , which showed a significant influence; therefore, H1-3 was supported. P-value of P-S fit was smaller than .000 with $\beta$ value of .421 , which showed a significant influence; therefore, H1-4 was supported. The 4 
sub-dimensions had positive effects on affective commitment; however, J-O Fit did not reach a significant level.

Table2. The Regression Analysis

\begin{tabular}{|c|c|c|c|c|c|}
\hline \multirow{3}{*}{$\begin{array}{l}\text { Independent } \\
\text { variable: }\end{array}$} & \multirow{2}{*}{\multicolumn{2}{|c|}{$\begin{array}{c}\text { Dependent variable: } \\
\text { Model } 1\end{array}$}} & \multicolumn{2}{|c|}{ affective commitment } & \multirow{3}{*}{$\frac{\text { Model } 3}{\beta(\mathrm{p})}$} \\
\hline & & & Mode & & \\
\hline & $\beta(p)$ & VIP & $\beta(p)$ & VIP & \\
\hline $\mathrm{Age}^{\mathrm{a}}$ & $.045(.614)$ & 1.656 & $-.077(.259)$ & 1.761 & $-.125(.054)$ \\
\hline $\begin{array}{l}\text { The duration } \\
\text { staying in } \\
\text { Taiwan }\end{array}$ & $-.050(.596)$ & 1.843 & $.039(.576)$ & 1.875 & $.083(.224)$ \\
\hline $\begin{array}{l}\text { Work } \\
\text { experience a }\end{array}$ & $.000(.998)$ & 1.772 & $-.050(.462)$ & 1.787 & $-.096(.145)$ \\
\hline Industry type ${ }^{a}$ & $.080(.339)$ & 1.464 & $-.038(.552)$ & 1.571 & $-.067(.272)$ \\
\hline $\begin{array}{l}\text { Personal } \\
\text { income }^{\text {a }}\end{array}$ & $.016(.854)$ & 1.509 & $.068(.290)$ & 1.563 & $.115(.063)$ \\
\hline NI & $\begin{array}{l}.449(.000) \\
* * *\end{array}$ & 1.053 & & & \\
\hline P-J Fit & & & $.132(.044)^{*}$ & 1.626 & $.342(.335)$ \\
\hline P-O Fit & & & $.084(.204)$ & 1.763 & $.271(.460)$ \\
\hline P-G Fit & & & $.291(.000) * * *$ & 1.446 & $.246(.477)$ \\
\hline P-S Fit & & & $.421(.000)^{* * *}$ & 1.195 & $-.592(.066)$ \\
\hline P-J Fit $\times$ NI & & & & & $-.317(.516)$ \\
\hline P-O Fit $\times$ NI & & & & & $-.335(.525)$ \\
\hline P-G Fit $\times N I$ & & & & & $-.033(.947)$ \\
\hline P-S Fit $\times$ NI & & & & & $1.351(.003)^{* *}$ \\
\hline $\mathrm{R}^{2}$ & .010 & & .470 & & .544 \\
\hline (Adjusted R²) & -.014 & & .446 & & .514 \\
\hline$\Delta \mathrm{R}^{2}$ & .010 & & .460 & & .074 \\
\hline F change & .422 & & 43.797 & & 8.035 \\
\hline Sig F change & .833 & & .000 & & .000 \\
\hline
\end{tabular}

Hypotheses 2: The Test on Interactive Effects

Model 3 in Table 2 shows that national identification of Chinese immigrant wives strengthen the effect of P-E Fit on affective commitment $\left(\mathrm{R}^{2}=\right.$ .544. P-Value smaller than .001); therefore, H2 was supported. For subdimensions, the interactive effect between P-J Fit and national identification $(\mathrm{P}-\mathrm{J}$ Fit $\times \mathrm{N} 1)$ was insignificant $(\mathrm{P}-\mathrm{Value}$ greater than .05 with $\beta$ value of .317); therefore, H2-1 was unsupported. The interactive effect between P-O Fit and national identification $(\mathrm{P}-\mathrm{O}$ Fit $\times \mathrm{NI})$ was insignificant $(\mathrm{P}-\mathrm{Value}$ greater than 0.05 with $\beta$ value of -.335); therefore, $\mathrm{H} 2-2$ was unsupported. The interactive effect between $\mathrm{P}-\mathrm{G}$ Fit and national identification $(\mathrm{P}-\mathrm{G}$ Fit $\mathrm{x}$ N1) was insignificant ( $\mathrm{P}$-value greater than .05 with $\beta$ value of -.033); therefore, $\mathrm{H}$ 2-3 was unsupported. The interactive effect between P-S Fit and national 
identification ( $\mathrm{P}$ Value smaller than .01 with $\beta$ value of 1.351) was significant; therefore, H2-4 was supported.

Overall, P-E Fit can enhance the affective commitment of Chinese immigrant wives considerably, which is consistent with the propositions on $\mathrm{P}$ E Fit in related literature (Harris and Mossholder, 1996; Kristof-Brown, 1996). Three of the 4 sub-dimensions, P-J Fit, P-G Fit, and P-S Fit, exhibited significant effects, which is consistent with current research on P-J, P-G and PS Fit (e.g. Adkins et al., 1996; Tinsley, 2000; Chuang and Lin, 2005). P-O fit was insignificant; however, this result is consistent with the empirical research from Chuang and Lin (2005) in that the P-E Fit aspect may not have the same effect on a specific work attitude. P-O Fit may not have such a direct influence on them as P-J, P-G, and P-S Fit. Similarly, national identification significantly moderates the effect of P-E Fit on the affective commitment (Chiang, 1998; Keillor and Hult, 1999). However among sub-dimensions of P-E Fit, National identification only increases the influence of their P-S Fit on affective commitment considerably, because those who have stronger belongingness and commitment tend to agree with the leadership of Taiwanese supervisors. When their value matches that of their supervisors, the affective commitment tends to increase. This finding is consistent with a number of studies on J-S Fit (Meglino et al., 1989; Tsui and O'Reilly, 1989). A possible explanation for national identity having a negative effect on P-J Fit, P-O Fit, and P-G Fit is their disagreement on Taiwanese racial groups, social and cultural systems.

Figure 2 shows that national identification increases the P-E Fit of Chinese immigrant wives on affective commitment. Chinese immigrant wives with high national identity exhibited a more significant effect of PE Fit on affective commitment, which is greater compared to those with low national identification ( $\beta$ value .765> .478). Those who have higher national identification are more assured about their belongingness and agree more on Taiwanese value; consequently, they experience a superior fit into the environment and have enhanced affective commitment. By contrast, those with lower national identification are more sensitive to the differences in racial groups and cultural and socio-political systems, which hinder their adjustment; therefore, their affective commitment tends to be lower.

The effect of national identification on the 4 sub-dimensions within P-E Fit shows a significant moderating effect. The interactive analysis in Figure 3 shows that Chinese immigrant wives with higher national identity have a significant effect of P-E Fit on affective commitment compared with those with lower national identification ( $\beta$ value .697> .552). The results show that, when $\mathrm{P}-\mathrm{S}$ Fit is high, supervisors and subordinates can work toward consistent goals, have smoother communication, and eventually reach feasible outcomes. Those with higher national identification can accept their supervisors' value management; therefore, mutual trust, expected performance, and affective commitment increase. However, the results showed decreasing effects on P-J Fit, P-G Fit, and P-O Fit. The finding shows that they may feel that they are being treated unfairly at work, such as different pay (Wu, 2004; Chen, 2007) or social exclusion (Cheng, 2010). 
Figure 2. The Interaction between Personal and Environment Fit

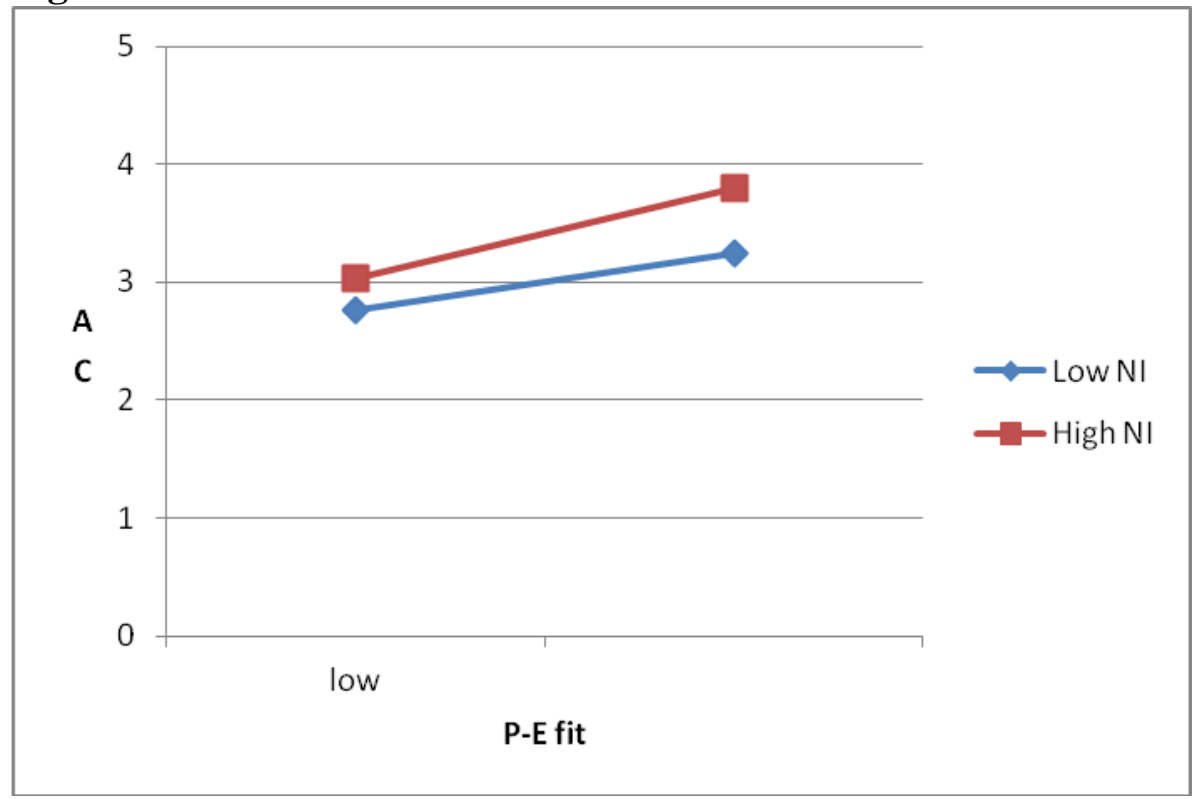

Figure 3. The Interaction between Person-Supervisor Fit

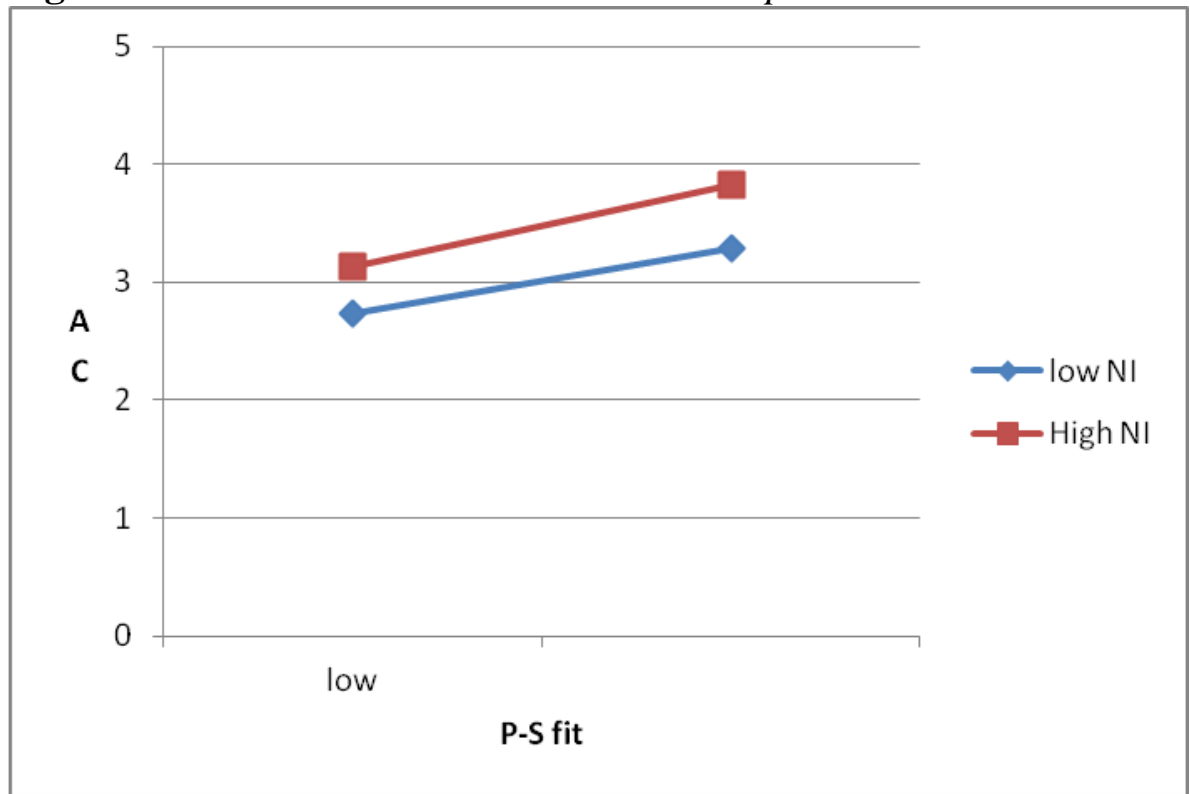

Note: High NI is for those whose NI higher than mean +1 standard deviation; Low NI is for those whose NI lower than mean - 1 standard deviation;

\section{Conclusion}

The results indicated that the P-E fit of Chinese immigrant wives influence their affective commitment considerably. Among the sub-dimensions of P-E fit, P-O Fit, P-J Fit, P-G Fit, and P-S Fit have considerable effects on affective commitment. Chinese immigrant wives with higher national identification experience an enhanced effect of P-E Fit on their affective 
commitment. However, among the four sub-dimensions of P-E Fit, national identification increases the effect of P-S Fit on affective commitment; however, it reduces the effect of P-J Fit, P-G Fit, and P-O Fit.

\section{Implications}

Firms must manage foreign immigrant wives to enhance the variety of human resources and pay attention to their work place fit; for example, assigning suitable jobs, providing appropriate training and consultation, and reasonable performance evaluations. National identification is also a considerable problem. The results show that, after adding the variable of national identification, a number of respondents exhibited a negative effect on P-E Fit (e.g., P-J Fit, P-O Fit, and P-G Fit). It implies that these Chinese immigrant wives felt that they were treated unfairly at their workplaces.

Because of the substantial influence of P-J Fit, P-G Fit, and P-S Fit on affective commitment, firms must assign suitable tasks for Chinese immigrant wives and maintain trustful relationships with them. A possible reason for which their P-O Fit showed no significant effect on affective commitment is their lack of work experience and connection to the culture and value of their firms. Therefore, firms must offer training education courses and team activities to enhance mutual understanding.

Additionally, P-J, P-O, and P-G originally have a positive influence on affective commitment; however, it had become a negative effect after considering national identification. The possible reason could be that they identified this nation but did not obtain equal treatment from their group and organization. This suggests that firms must evaluate their HRM practices and avoid the deed of equal work-unequal pay or unfair job assignment.

\section{Academic Implications and Suggestions}

P-E Fit and organizational commitment have considerable explanatory and predictable capabilities on the manner in which immigrant wives fit in at their workplaces. In addition, they have referral values on the HRM practices of employing immigrant workers. A number of findings were obtained after adding the variable of national identification. It implies that future research on the PE Fit of immigrant wives and HRM practices must focus on a number of mediating or moderating variables.

Most of the samples were obtained from Taipei and Kaohsiung, which may constrain the generalization capability. Future research can include areas other than metropolitan cities. Additionally, several Vietnamese and Indonesian immigrant wives reside in Taiwan. They experience another problem, that is, language barrier. Further insight and results can be obtained if they are included in future studies. It is also advisable to compare Taiwan with countries that have numerous immigrant wives. Furthermore, when future 
studies explore P-E Fit and affective commitment, other moderating effects (e.g., the locus of control, self-efficacy, and leadership) can be examined to expand the depth and width of the research.

\section{Acknowledgements}

We would like to express our sincere gratitude to H. I. Tsai, C. A. Lin, C.M. Lien and C. H. Wang for their contribution in collecting sample data.

\section{Reference}

Adkins, CL, Ravlin, EC and Meglino, BM (1996) Value congruence between coworkers and its relationship to work outcomes. Group and Organization Management 21(4):439-460.

Allen, NJ, and Meyer, JP (1991) A three-component conceptualization of organizational commitment. Human Resource Management Review 1:61-98.

Autry, CW, and Daugherty, PJ (2003) Warehouse operations employees: Linking person-organization fit, job satisfaction, and coping responses. Journal of Business Logistics 24: 171-197.

Bretz, RD, and Judge, TA (1994) Person-organization fit and the theory of work adjustment: Implications for satisfaction, tenure, and career success. Journal of Vocational Behavior 44: 32-54.

Cable, DM, and Judge, TA (1996) Person organization fit, job choice decisions, and organizational entry. Organizational Behavior and Human Decision Processes 67: 294-311.

Cable, DM, and DeRue, DS (2002) The convergent and discriminate validity of subjective fit perceptions. Journal of Applied Psychology 87(5): 875-884.

Caldwell, DF, and O'Reilly, CA (1990) Measuring person-job fit with a profilecomparison process. Journal of Applied Psychology 75(6): 648-657.

Carmeli, A (2005) Perceived external prestige, affective commitment, and citizenship behaviors. Organization Studies 26(3): 443-464.

Chatman, JA (1991) Matching people and organizations: Selection and socialization in public accounting firms. Administrative Science Quarterly 36: 459-484.

Chen, MS (1998) Research on the influence of employee's personality and QWL on work attitude and job performance in retail industry (Unpublished doctoral dissertation). University of National Sun Yat-sen, Kaohsiung, Taiwan.

Cheng, CY (2010) The effectiveness evaluation of training programs to immigrant spouses (Unpublished investigation report). Taiwan Research and Development Center of Labor Education.

Chu, PL (2005) A research on the managerial problems of foreign workers and immigrant spouses. Foundation of National Policies and Research 094-003.

Chu, ZZ, and Liu, CJ (2005) An exploration on Chinese immigrant wives' identification in Taiwan. Community Development Quarterly 112: 179-196.

Chuang, AC, and Lin, HY (2005)An investigation of the effect of person-environment fit on work attitudes and behaviors. Taiwan Academy of Management Journal 5(1): 123-148. 
Coleman, DF, Irving, GP, and Cooper, CL (1999) Another look at the locus of control organizational commitment relationship: It depends on the form of commitment. Journal of Organizational Behavior 20: 995-1001.

Cox, TH, and Blake, S (1991) Managing cultural diversity: Implications for organizational competitiveness. Academy of Management Executive 5: 45-56.

Driskell, JE, Hogan, R, and Salas, E (1987) Personality and group performance. In C. Hendrick (Eds.), Personality and Social Psychology Review 91-112. Beverly Hills, CA: Sage.

Edwards, JR (1991) Person-job fit: A conceptual integration, literature review, and methodological critique. In CL Cooper and IT Robertson (Eds.), International review of industrial and organizational psychology 283-357. New York: John Wiley and Sons.

Furnham, A (1994) Personality at work. London: Routledge.

Hackman, JR, and Morris, CG (1975) Group tasks, group interaction process, and group performance effectiveness: A review and proposed integration. In L. Berkowitz (Eds.), Advances in experimental social psychology 45-99. New York: Academic Press.

Hair, JF Jr., Black, WC, Babin, BJ, and Anderson, RE (2010) Multivariate Data Analysis, 7th (Ed.), Upper Saddle River, NJ: Prentice Hall.

Harris, SG, and Mossholder, KW (1996) The affective implications of perceived congruence with culture dimensions during organizational transformation. Journal of Management 22: 527-547.

Haythorn, WW (1968) The composition of groups: A review of the literature. Acta Psychological 28:97-128.

$\mathrm{He}, \mathrm{G}$, and Guo,Y (2000) Nationalism, national identity and democratization in China. Hampshire, England: Ashgate.

Herndon, NC, Fraedrich, JP, and Yeh, QJ (2001) An investigation of moral values and the ethical content of the corporate culture: Taiwanese versus U.S. sales people. Journal of Business Ethics 30(1):73-85.

Hoerr, J (1989) The payoff from teamwork, Business Week, July 10 56-62.

Holland, JL (1985) Making vocational choices: A theory of vocational personalities and work Environments. Princeton, NJ: Prentice Hall Inc.

Hollenbeck, JR (1989) Control theory and the perception of work environments: The effects of focus of attention on affective and behavioral reactions to work. Organizational Behavior and Human Decision Process 43: 406-430.

Huntington, SP (1993) The clash of civilizations. Foreign Affairs 72(3): 22-49.

Jackson, SE (1992) Team composition in organizational settings: Issues in managing an increasingly diverse workforce. In S. Worchel, W. Wood, and JA Simpson (Eds), Group Process and Productivity 136-180. Newbury Park, CA: Sage.

Jiang, I-Hua (1998) Racial justice and national identification. The Conference on Racial Justice and Security of Human Right. Taipei, The Incidence of 228 Memorial Foundation.

Judge, TA, and Ferris, GR (1992) The elusive criterion of fit in human resource staffing decisions. Human Resource Planning15(4): 47-67.

Judge, TA and Bono, JE (2001) Relationship of Core self-Evaluation Traits- SelfEsteem, Generalized Self-Efficacy, Locus of Control and Emotional Stabilitywith Job Satisfaction and Job Performance: A Meta-Analysis, Journal of Applied Psychology 86(1): 80-92.

Keillor, BD, and Hult, GTM (1999)A five-country study of national identity: Implications for international research and practice. International Marketing Review 16(1): 65-82. 
Keillor, BD, Hult, GTM, Erffmeyer, RC, and Babakus, E (1996) NATID: The development and application of a national identity measure for use in international marketing. Journal of International Marketing 4(2):57-73.

Kinicki, AJ, and Vecchio, RP (1994) Influences on the quality of supervisorsubordinate relations: The role of time-pressure, organizational commitment, and locus of control. Journal of Organizational Behavior 15:75-82.

Klimoski, RJ, and Jones, RG (1995) Staffing for effective group decision making: Key issues in matching people and teams? In R. Guzzo \& E. Salas (Eds.), Team effectiveness and decision making in organizations 291-332. San Francisco: Jossey-Bass.

Kristof-Brown, AL (1996) Person-organization fit: An integrative review of its conceptualizations, measurement, and implications. Personnel Psychology 49:1-49.

Kristof-Brown, AL, and Stevens, CK (2001) Goal congruence in project teams: Does the fit between members' personal mastery and performance goals matter? Journal of Applied Psychology 86:1083-1095.

Kristof-Brown, AL, Zimmerman, RD and Johnson, EC (2005) Consequences of individuals' fit at work: A meta-analysis of person-job, person-organization, person-group, and person-supervisor fit. Personnel Psychology 58:281-342.

Lee, WL (1998) The Effect of an Internal Job Change System and Personal Characteristics on Transferees' Person-Environment Fit in the process of Organizational Change. A Master Degree Dissertation of Graduate Institute of Human Resource Management, National Central University.

Luthans, F, Baack, D, and Tayolr, L (1987) Organizational commitment: Analysis of antecedents. Human Relations 40(4): 219-236.

McIntyre, N, Srivastava, A and Fuller, JA (2009) The Relationship of Locus of Control and Motives with Psychological Ownership in Organizations. Journal of Managerial 21(3):383-401.

Meglino, BM, and Ravlin, EC, and Adkins, CL (1989) A work values approach to corporate culture: A field test of the value congruence process and its relationship to individual outcomes. Journal of Applied Psychology 74:424-432.

Meyer, JP, and Allen, NJ (1990) A three-component conceptualization of organizational commitment. Human Resource Management Review 1: 61-98.

Meyer, JP, Allen, NJ, and Smith, CA (1993) Commitment to organizations and occupations: Extension and test of the three-component conceptualization. Journal of Applied Psychology 78: 538-551.

Millward, LJ, and Brewerton, PM (2002) Psychological contracts: Employee relations for the twenty-first century? International Review of Industrial and Organizational Psychology 15: 1-61.

Mohamed, F, Taylor, GS, and Hassan (2006) Affective commitment and intent to quit: the impact of work and non-work related issues. Journal of Managerial Issues 18(4):512-529.

Mowday, RT and Poter, LW, and Steers, RM (1982) Employee -Organization Linkages. New York: Academic Press.

Ng, TWH, Sorensen, K L and Eby, LT (2006) Locus of control at work: a metaanalysis. Journal of Organizational Behavior 27: 1057-1087.

Namini, S; Appel, C; Jürgensen, R and Murken, S (2010) How is well-being related to membership in new religious movements? An application of person-environment fit theory. Applied Psychology 59(2):181-201.

Podsakoff, PM, MacKenzie, SB, Lee, JY and Podsakoff, NP (2003) Common Method Biases in Behavioral Research: A Critical Review of the Literature and Recommende Remedies. Journal of Applied Psychology 879-903. 
Posner, BZ, Kouzes, JM, and Schmidt WH (1985) Shared values make a difference: An empirical test of corporate culture. Human Resource Management 24: 293309.

Ravlin, EC, and Meglino, BM (1987) Effect of values on perception and decision making: A study of alternative work value measures. Journal of Applied Psychology 72: 666-673.

Rotter, J (1954) Social learning and clinical psychology. Englewood Cliffs, NJ: Prentice Hall.

Rotter, JB (1966) Eneralized expectancies for internal versus external control of reinforcement. Psychological Monographs 80: 1-27.

Saks, AM, and Ashforth, BE (1997) A longitudinal investigation of the relationships between job information sources, applicant perceptions of fit, and work outcomes. Personnel Psychology 50: 395-426.

Schneider, B (1987) The people make the place. Personnel Psychology 40: 437-453.

Schyns, B, and Collani, GV (2002) A new occupational self-efficacy scale and its relation to personality constructs and organizational variables. European Journal of Work \& Organizational Psychology 11(2): 219-241.

Shaw, ME (1981) Group dynamics: The psychology of small group behavior ( $\left.3^{\text {rd }} \mathrm{ed}.\right)$. New York: McGraw-Hill.

Singh, V, and Point, S (2004) Strategic responses by European companies to the diversity challenge: An Online Comparison. Long Range Planning 37(4): 295-318.

Smith, AD (1991) National Identity. London: Penguine Books.

Spector, PE (1988) Development of the work locus of control scale. Journal of Occupational Psychology 61: 335-340.

Tinsley, HEA (2000) The congruence myth: An analysis of the efficacy of the personenvironment fit model. Journal of Vocational Behavior 56: 147-179.

Tsui, AS, and O'Reilly, CA (1989) Beyond simple demographic affects: The importance of relational demography in superior-subordinate dyads. Academy of Management Journal 32: 402-423.

Vandenberghe, C, Bentein, K, and Stinglhamber, F (2004) Affective commitment to the organization, supervisor, and work group: Antecedents and outcomes. Journal of Vocational Behavior 64(1):47-71.

Wang, Q, Bowling, N, and Eschleman, K (2010) A meta-analytic examination of work and general locus of control. Journal of Applied Psychology 95(4): 761-768.

Weigand, RA (2007) Organizational diversity, profits and returns in US firms. Problems and Perspectives in Management 5(3): 69-83.

Weiss, HM (1978) Social learning of work values in organizations. Journal of Applied Psychology 63: 711-718.

Weldon, E and Weingart, LR (1993) Group goals and group performance. British Journal of Social Psychology 32: 307-334.

$\mathrm{Wu}, \mathrm{SC}$ (2004) From the perspective of ecological system and related research to explore Southern Asian immigrant wives' education environment and experiences on developmental delayed children. Community Development Quarterly 105: 159-175.

$\mathrm{Wu}$, TS, Lee, KC, Liu, YS, and Ou, HM (1996) A research on the modifications of job value questionnaires. Taipei. Youth Consultation Commission, Execution Yuan of R.O.C.

Young, AM, and Hurlic, D (2007) Gender enactment at work: The importance of gender and gender-related behavior to person-organizational fit and career decisions. Journal of Managerial Psychology 22(2): 168-187. 
Zenger, TR, and Lawerence, BS (1989) Organizational demography: The differential effects of age and tenure distribution on technical communication. Academy of Management Journal 32: 353-376. 